\title{
Report of the Panel on Therapy
}

Chairman: S. G. Browne (Nigeria); Secretary: M. F. R. Waters (UK);

Members: A. M. Alonso (Brazil); A. Baccareda Boy (Italy); J. Barba Rubio (Mexico); T. F. Davey (UK); K. F. Schaller (Ethiopia); S. Schujman (Argentina); Gloria Pérez-Suáre\% (Mexico); J. Aguiar Pupo (Brazil); 
Rodolphe A. Bréchet (Angola); J. Languillon (France); W. O. Opromolla (Brazil); Renê Rollier (Marrocos); Manucl S. Silva (Portugal); $\Lambda$. 'T. Roy (India); J. Carlos Gatti (Argentina).

'The following members of the Pancl contributed by correspondence to its deliberations, but were not present at the meetings of the Pancl:

P. Laviron (France); H. Floch (France); Latif K. Hanna (Egypt); Y. Hayashi (Japan); K. Ramanujani (India).

In presenting this Report of the Pancl on 'Therapy, we must state at the outset that in spite of much good work at various centres on several new drugs, there is no spectacular progress to record in the therapy of leprosy since the last Congress. No one drug secms to be outstanding in its action, or likely to supplant dapsone on the grounds of thereapeutic efficacity or cost or ease of administration.

I. SUlPHONE THERAPY. We consider that dapsone (DI)S) is still the drug of choice for general use in active leprosy. Its well-known advantages and disadvantages have been stated in previous reports. We wish, howcver, to draw attention to the following points:

(a) The main shortcorning of dapsone is its stow effect (clinical, bacteriological and histological) in the serious forms of leprosy. This is probably related to such factors as the essential chronicity of the infection and the long generation time of $M$. leprae. While dapsone may produce bacterial negativity and clinical arrest in lepromatous leprosy in from three to six years, up to 50 per cent of patients in some countries may still be bacteriologically positive at the end of that time. Whatever their proportion to the total number of patients who respond satisfactorily, these 'persistent positive cases' constitute a therapeutic challenge. Poor absorpsion from the intestine for one reason of another is a possible explanation, but bacterial resistance may occur. Further investigation is required. Moreover, the removal of non-viable acid-fast debris may be abnormally protracted in some patients, and the tissues in others may be persistently hypersenstitive to acid-fast material.

(b) The duration of treatment. Previous Congresses have given general guidance, and there has been no great departure from former practice. There is now, however, a greater readiness to advise that treatment should continue for life after clinical and bacteriological arrest of lepromatous or borderline disease, with half the standard thereapeutic dose. After arrest of the disease, regular bacteriological examinations are advocated as the best and carliest means of detecting relapse.

(c) Dosage. In an attempt to reduce the incidence of neuritis and of all types of reaction, many workers have been using a smaller initial oral dose, and a lower maximum dose than has been recommended in the past. Although we consider that each area must individually decide its own optimum dosage schedule, we note that many workers have obtained excellent results with $25 \mathrm{mg}$. twice weekly initially, rising to a maximum of 
$200 \mathrm{mg}$. twice weekly. For mass treatment by medical auxiliaries, we do not recommend different dosage schedules for the different types of leprosy, though we would add that the initial dose should be small and the increments made slowly.

(d) Injectable repository dapsone. Various preparations which give adequate blood levels for two weeks are in general use, but as yet no suspension of dapsone for injection once every four weeks has been forthcoming.

(e) Prophylaxis. 'There is insufficient evidence to enable us at this stage to advise either on the efficacity of the prophylactic use of sulphones or on the advisability of giving sulphones prophylactically.

2. Thinmbutosine (1)PT, "Ciba igo6) has won widespread acceptance as a uscful alternative drug to dapsone, though the devclopment of resistance after two years has been reported from many countries. It has in particular proved useful in patients intolerant to dapsone. An injectable preparation of thiambutosine is under investigation.

3. DITOPHAL (ETISUL) continues to evoke contradictory comments. The consensus of opinion would, however, scem to be that while ditophal has an undoubted action in leprosy when given alone (though resistance may develop), its addition to standard dapsone therapy for a longer or shorter time, in an untreated or in a treated patient in a stationary condition, does not generally result either in a more rapid clinical or bacteriological improvement than with dapsone alone, or in a material shortening of the total length of treatment required. Notwithstanding good reports from some centres, ditophal has not received consistent acclaim. Its odour is a disadvantage in most countries, and its cost makes it an uneconomic drug when its use is not followed by a definite shortening of the period of treatment. Local dermatitis or a generalised cutaneous hypersenstitivity precipitated by its use varies in incidence from negligible to very high. Where the clinical forms of leprosy are most severe, the opinions concerning the drug are least commendatory. Its future sphere of usefulness may well be limited.

4. THE LONG-ACTING SUlphonamides have been studied now for five years. Early reports indicated that sulphamethoxypyrazine (also known as sulphamethoxypyridazine) sulphadimethoine gave uniformly good results in small series of patients with tuberculoid leprosy, but that the bacteriological improvement in patients with lepromatous leprosy was not consistently good.

More recently, other long-acting sulphonamides have been tried at a few centres, and preliminary reports covering up to two years suggest that these compounds may have a definite place in anti-leprosy therapy. Mention may be made of acetylsulphamethoxypyrazine (acetyl-Kelfizine, or I I, 589 R.P.), and Ro 4-4393. In lepromatous leprosy, their action seems to be comparable to that of the sulphones. No adverse side-effects have been reported to date, and the incidence of drug-induced reaction is not greater than with the sulphones. According to some workers, but not to 
others, the action of these drugs in tuberculoid leprosy may be more rapid than that of the sulphones. Expanded trials are indicated in this promising scries of drugs. While those at present under trial cannot be expected to replace dapsone in mass therapy, the advantages of a drug that is given orally, once a week, are evident.

\section{O'THER DRUGS}

(a) Diaminodephenyl sulphoxide (DDSO) has becn found too nephotoxic for general use.

(b) Thiacetazone (thiosemicarbazone, TB-I). In certain hands thiacetazone continues to give satisfactory results, although the emergence of drug resistance must be borne in mind.

(c) Streptomycin and Isioniazed (INH, isonicotinic hydrazide). Insufficient new information has been gained during the past live years for any addition to be made to the last Congress report.

(d) B663, a rimino-compound (aposaframin), has given good results both alone and in combination with dapsone in a small series of patients. Further trials are indicated.

(e) Rifamycin. This drug has been studied in only a very few patients. Further reports are required before it can be evaluated.

(f) Vadrine, cycloserine, kanamycin, and many other compounds reported on by different centres may, for various reasons, have a limited sphere of usefulness, but none appears to be sufficiently promising for widespread use to be recommended.

6. General considerations. A therapeutic agent capable of several diverse actions is required in leprosy. This ideal agent should be rapidly bactericidal, it should facilitate the clearance and removal from the body of bacterial debris, and it should minimise or abolish the pathological effects of the presence of living or dead acid-fast material in the tissues. Several drugs are either bactericidal to $M$. leprae in nine months or so, or prevent their multiplication, but all workers are agreed that this desirable result is not equivalent to clinical cure of leprosy. 'The main kinds of leprosy for which such an agent is urgently required are the long-standing lepromatous, the severe and rapidly-advancing lepromatous, the reactional tuberculoid, the reactional borderline, and all kinds of leprosy characterised by severe neuritis. Perhaps the concurrent use of more than one agent will eventually be the answer to the problem.

7. Bacteriology. The Panel considers that uniformity in expressing the Bacterial Index is desirable in all reports of thereapeutic trials. Some members were of opinion that a logarithmic scale such as Ridley's should be studied with a view to its eventual adoption. Meanwhile, we are strongly of opinion that all reports should include information concerning the morphology of $M$. leprae as seen in smear preparations made according to standard techniques, expressing as percentages 'normal solid-staining rods' and 'non-solid forms' of all kinds. 